\title{
Range-reference determination of lymphocyte subsets in Moroccan blood donors
}

*Touil $\mathrm{N}^{1}$, Hadef $\mathrm{R}^{2}$, Lemnouer $\mathrm{A}^{3}$, Zrara A ${ }^{4}$, Sbai AI ${ }^{4}$, Belfquih $\mathrm{B}^{1}$, Mrani $\mathrm{S}^{1}$, Benkirane $\mathrm{A}^{2}$, Ouaaline $\mathrm{M}^{4}$, Mrabet $\mathrm{M}^{4}$

1. Laboratoire de Virologie, Hôpital Militaire d'Instruction Med V Rabat, Um5, Souissi, Morocco

2. Centre de Transfusion Sanguine, Hôpital Militaire d'Instruction Med V Rabat, Morocco

3. Service de Bactériologie, Hôpital Militaire d'Instruction Med V Rabat, Morocco

4. Service d'Hygiène et Médecine de collectivité, Hôpital Militaire d'Instruction Med V Rabat, Morocco

\begin{abstract}
Background: Information on lymphocyte populations (T, B, and Natural killer cells) and subpopulations (CD4 and CD8) in Morocco is scarce if not inexistent.

Objective: To establish a reference value of these cells in 242 Moroccan young adult blood donors by flow cytometry.

Results: Smokers had significantly higher total leukocyte count $(p<0.001)$, total lymphocyte count $(p<0.0001)$ and higher CD3+CD4+ cells $(p<0.0001)$. The percentage of CD3-CD56+ subsets was affected by smoking $(p<0.01)$.

Our analysis positively correlate with previous observations of an increase of absolute $\mathrm{CD} 4+\mathrm{T}$ cells, with no changes in other lymphocyte subset cells in smokers.

The lymphocyte subpopulation distributions for all antigens were found to be similar to those reported in Saudi and Italian adults, while higher levels were reported for the same gender in other countries, especially Ghana and Kuwait.

Conclusion: The international classification standards of the HIV-infected subjects according to their rates of CD4 are applicable to the present study's population.

Key words: Young Moroccan adults, flow cytometry; Lymphocyte counts, cigarette effects

African Health Sciences 2012; 12(3): 334 - 338 http://dx.doi.org/10.4314/ahs.v12i3.14
\end{abstract}

\section{Introduction}

Human peripheral blood immunologic cell counts may vary among healthy individuals in terms of age, sex, stress, race, smoking habits, diet and physical exercise. ${ }^{1,2,3,4,5,6}$ These variations may also be due to pathologies that involve the immune system (infections, acquired immunodeficiency syndromes, immuno-heamatological and auto-immune disorders), medication or during immunotherapy. ${ }^{7}$ Past research has demonstrated country-related differences of CD4 ranges, which are essential biomarkers in the following and the monitoring responses to antiviral therapies in Human Immunodeficiency Virus-infected individuals. ${ }^{8}$

In this regard, it is of great importance to establish a referential range of lymphocyte subsets (more importantly CD4) for each population; thus, differences between normal and pathologic values

\author{
*Corresponding author: \\ Nadia Touil \\ Service de Virologie \\ Hôpital Militaire d'Instruction Med \\ UM5 Souissi \\ Rabat Morocco \\ Phone: (+212) 422-015-54 / 376-823-74 \\ Email: ntouil2003@gmail.com
}

can be established, knowing that these pathologic values cannot be reliably quantified if they are not rigorously controlled and compared to the normal ones. These values may be determined through outcome measures such as flow cytometry, being such an easy, straightforward method for immunophenotyping lymphocyte subsets. Therefore, our study was carried out to establish reference value for lymphocyte subsets in a group of healthy Moroccan blood donors by flow cytometry.

\section{Methods}

\section{Study population}

242 healthy military blood donors were the informants in this study. They were all considered free of clinical infection; check-up of blood pressure, pulse rate, and hemoglobin were controlled in the Rabat Military Hospital Blood Transfusion Center. All donors were screened for syphilis, HIV $^{1,+2}$, viral hepatitis $B$ and $C$ infections by routine serological tests respectively Biokit hemaglutination assay, Biorad $\mathrm{HIV}^{1,+2}$, Enzygnot AgHBs and Murex HCV and were negative. Blood samples were collected in EDTA-tubes and used within 6 hours of storage at temperature room. Specimens including 222 males and 20 females were analyzed, as well.

African Health Sciences Vol 12 No 3 September 2012 


\section{Flow Cytometry}

Dual labeled monoclonal antibodies (CD3Fluorescein IsothioCyanate (FITC)/ CD4PhycoErythrin (PE), CD3-FITC/CD8-PE, CD3FITC/CD56-PE, CD3-FITC/CD19-PE, CD45FITC/CD14-PE and IgG1-FITC/IgG2a-PE isotype control (opticlones from Immunotech, Beckmann Coulter, Marseille, France) were used for the direct immunostaining. $10 \mu \mathrm{l}$ of every MAb was added to $50 \mu \mathrm{l}$ of whole blood adjusted to 5000 cells $/ \mu \mathrm{l}$, incubated 10 minutes in dark at room temperature. Afterwards, the cells were lysed with $\mathrm{NH}_{4} \mathrm{Cl}$ for 30 minutes and were immediately analyzed by flow cytometer (Beckman Coulter: Epics XL equipped with Argon laser excitation at $488 \mathrm{~nm}$ ).

The panel used was the same as recommended by the CDC for performing CD4+ T-cell determinations in individuals infected with HIV. ${ }^{9}$ Lymphocyte analysis was carried out with a particular attention to the purity of the lymphocyte gate: more than $95 \%$ was the maintained purity level. T Lymphocytes were defined with CD3 expression. As to the lymphocyte sub-populations, only cells with double staining were considered positive for $\mathrm{T} 4$ and $\mathrm{T} 8$ cells respectively $\mathrm{CD} 3+\mathrm{CD} 4+$ and $\mathrm{CD} 3+\mathrm{CD} 8+$ cells. B and NK (Natural Killer) cells were CD19+CD3- and CD56+CD3- respectively.

We resorted to a dual-platform approach to generate absolute lymphocyte subset cell counts using a hematology analyzer (ACT-10). The absolute values for T4 and T8 cells were obtained by multiplying the percentage of lymphocytes which co-express CD 3 and CD4, CD 3 and CD 8 and that the value obtained by the absolute lymphocyte count. CD19 and CD56 absolute values were obtained by multiplying their percentages by the absolute lymphocyte count. The lymphocyte recovery and the consistency of some check sums were rigorously performed as internal quality controls.

\section{Analytical tools}

Differences between means of males and females, smokers and non-smokers were compared by Kruskal-Wallis test. The percentages were compared by ANOVA. The data of hematological studies were used for comparison. $p$-values less than 0,05 were considered to reflect the significance level.

\section{Ethical consideration}

All donnors gave informed consent and the donation was voluntary.

\section{Results}

The age of the scrutinized population ranged between 19 and 49 years with a means value of 27,8 years. The distribution of individuals according to their sex and smoking habits is shown in table I: The predominant sex in the studied group was male. Indeed, the sex ration $\mathrm{M} / \mathrm{F}$ is 11,1 : Table 1 shows that $71 \%$ of individuals are non-smokers.

\section{Table 1: Study population characteristics}

\begin{tabular}{lllc}
\hline Characteristics & Males & Female & Total \\
\hline Smokers & 69 & 2 & 71 \\
Non-smokers & 151 & 20 & 171 \\
Total population & 220 & 22 & 242 \\
\hline
\end{tabular}

Table 2 shows the complete blood count for the study group. The absolute counts of human leukocyte and total lymphocyte in the study population are respectively $6,822 \times 103 \pm 1,687 \times 103$ and $1876 \pm 500$ cells $/ \mu 1$. No statistically significant differences were found between males and females.

Table 2: Complete blood count data in 242 blood donors

\begin{tabular}{llll}
\hline Parameters & Mean & Minimum & Maximum \\
\hline WBC $\left(10^{3}\right)$ & 6,8 & 3700 & 11700 \\
RBC $\left(10^{6} / \mu \mathrm{l}\right)$ & 5,1 & 3,9 & 13,8 \\
Hgb $(\mathrm{g} / \mathrm{dl})$ & 15,0 & 11,6 & 18 \\
PCV $(\%)$ & 45,6 & 4,0 & 95,9 \\
MCV (fL) & 88,5 & 20,6 & 105,8 \\
MCHC (g/dl) & 31,7 & 3,1 & 30,6 \\
Plt $\left(10^{3} / \mu \mathrm{l}\right)$ & 215,4 & 24 & 374 \\
\hline
\end{tabular}

WBC: Whole blood cells; RBC: Red blood cells; Hgb: haemoglobin; PCV: Hematocrit or packed cell volume; MCV: Mean corpuscular volume; MCHC: Mean corpuscular hemoglobin concentration; Plt: Platelets, Ly: Lymphocytes. 
The relative and absolute numbers of lymphocyte subpopulations with their corresponding standard deviations are given in table 3 . For normal values of various lymphocyte components, we found that the mean values of 1876 cells $/ \mu \mathrm{l}(28,44 \%)$ for total lymphocytes, 871 cells/ $\mu \mathrm{l}(53 \%)$ for CD3+CD4+ cells, 637,54 cells $/ \mu \mathrm{l}(33 \%)$ for CD $3+\mathrm{CD} 8+$ cells, 211 cells $/ \mu \mathrm{l}(11,73 \%)$ for CD3-CD56+ and 159 cells $/ \mu \mathrm{l}(5,26 \%)$ for CD19.

Table 3: Relative and absolute lymphocyte subset population counts

\begin{tabular}{|c|c|c|c|}
\hline Parameters & Mean & Minimum & Maximum \\
\hline$\overline{\mathrm{Ly}}(\%)$ & 28,44 & 11 & 47 \\
\hline $\mathrm{Ly} / \mu \mathrm{l}$ & 1876 & 900 & 3600 \\
\hline CD3 $(\%)$ & 74,3 & 52 & 89 \\
\hline $\mathrm{CD} 4(\%)$ & 52,9 & 23 & 68 \\
\hline CD8(\%) & 32,9 & 17 & 57 \\
\hline CD56(\%) & 11,7 & 2 & 34 \\
\hline CD19(\%) & 5,26 & 1 & 12 \\
\hline CD3 cells $/ \mu \mathrm{l}$ & 1431,5 & 605 & 3026 \\
\hline CD4 cells $/ \mu \mathrm{l}$ & 871,8 & 363 & 2278 \\
\hline CD8 cells $/ \mu \mathrm{l}$ & 637,5 & 252 & 1512 \\
\hline CD56 cells $/ \mu \mathrm{l}$ & 1211 & 300 & 1124 \\
\hline CD19 cells $/ \mu \mathrm{l}$ & $11 \quad 59$ & 3 & 319 \\
\hline
\end{tabular}

Absolute and relative counts of lymphocytes and lymphocyte subpopulations in non-smokers and smokers are given in table 4 . With the exception of CD3/CD56+ lymphocytes ( $\mathrm{p}=0.01)$, no significant differences between smokers and non-smokers were identified for the percentages among all investigated subpopulations.

Table 4: Absolute and relative counts of lymphocytes and lymphocyte subpopulations in non-smokers and smokers

\begin{tabular}{llll}
\hline & $\begin{array}{l}\text { Smokers } \\
\text { Nb: } 71\end{array}$ & $\begin{array}{l}\text { Non-smokers } \\
171\end{array}$ & \\
\hline WBC $\left(10^{3}\right)$ & $7,54 \pm 1,74$ & $6,55 \pm 2,58$ & $\mathrm{p}<0,001$ \\
Ly $(\%)$ & $29,82 \pm 6$ & $27,87 \pm 7$ & $\mathrm{p}=0,04$ \\
Ly & $2208 \pm 562$ & $1797,8 \pm 443$ & $\mathrm{p}<0,001$ \\
CD3(\%) & $74,0 \pm 6,13$ & $74,5 \pm 6,9$ & $\mathrm{p}=0,29$ \\
CD4(\%) & $45,18 \pm 8,05$ & $45,5 \pm 6,9$ & $\mathrm{p}=0,38$ \\
CD8 $(\%)$ & $31,11 \pm 6,55$ & $33,75 \pm 6,53$ & $\mathrm{p}=0,20$ \\
CD56(\%) & $12,15 \pm 5,9$ & $10,61 \pm 6,95$ & $\mathrm{p}=0,01$ \\
CD19(\%) & $7,79 \pm 4,2$ & $7,04 \pm 3,8$ & $\mathrm{p}=0,20$ \\
CD3 & $1639 \pm 480$ & $1346 \pm 379$ & $\mathrm{p}<0,0001$ \\
CD4 & $998 \pm 820$ & $731 \pm 224$ & $\mathrm{p}<0,0001$ \\
CD8 & $692 \pm 258$ & $615 \pm 211$ & $\mathrm{p}<0,052$ \\
CD56 & $234 \pm 170$ & $221 \pm 127$ & $\mathrm{p}=0,84$ \\
CD19 & $145 \pm 98$ & $124 \pm 71$ & $\mathrm{p}=0,17$ \\
\hline
\end{tabular}

The $p$ values were determined by the Kruskall-Wallis test.

In contrast, absolute leukocyte counts according to smoking status showed several significant differences in lymphocyte subpopulations between smokers and non-smokers. In addition to an increased number of peripheral white blood cells, smokers also had a higher total count of blood lymphocytes. This increase is mostly due to an increase of $\mathrm{T}$ lymphocytes (CD3+), especially of CD4+ lymphocytes. Statistically, no significant increase could be detected for CD8+ cells, B and NK lymphocytes.

\section{Discussion}

The present study was undertaken to determine relative and absolute numbers in human peripheral blood lymphocyte subsets among 242 Moroccan blood donors to establish a reference range. Our population was relatively young, with $90 \%$ of male sex and $70 \%$ non-smokers. This is not surprising for Moroccan military population, because the majority of the Moroccan military people are males, retiring at 50 years old. All individuals had a normal complete blood count. To the best of our knowledge, this is the first study reported for the Moroccan population concerning relative and absolute baseline lymphocyte/ $\mu$ l subsets.

The number of the circulating white blood cells was shown to be influenced by smoking habits, which confirmed the previous data concerning the impacts of cigarette smoke on blood cells. Indeed, leukocytosis in smokers has been well established based on cross-sectionaland longitudinal studies in the general population. ${ }^{10,11}$ Moreover, the absolute CD4 lymphocyte counts were higher in smokers than in non smokers. In contrast, the other lymphocyte subpopulations investigated were not affected by smoking. The smoking effect has been reported to increase the number of $\mathrm{T}$ cells and mainly CD4 peripheral blood lymphocytes. ${ }^{11,12}$

When we compared lymphocyte subset counts (CD4 and CD8) found in the present study with other published series in other countries such as Saudi Arabia and Italy similar ranges were found. ${ }^{13,14}$ In contrast to other countries, especially Ghana and Kuwait, higher level of CD4 cells was reported for the same gender. ${ }^{15,16}$ In those studies, the smoking habits of healthy control groups were not reported. Despite using the same panel of monoclonal antibodies as recommended by the $\mathrm{CDC}^{9}$ observed differences might be due to differences in the 
methodological variables which were not subject to any restrictive criteria due to a lack of a wide consensus such as lysing solutions, time and temperature of sample incubation, fixative employment and staining technique. ${ }^{14,17,18}$ We have used a dual platform to determine the lymphocyte subset values; but did not use triple or quadruple staining, which might reduce inter-laboratory variations as reported in many studies ${ }^{19,20}$ In addition, these differences of lymphocyte numbers can be associated with sex and age. Population parameters, however, were not well defined.

\section{Conclusion}

This study cannot be representative of Moroccan population. However, one can consider the values that we found as normal values in a young representative sample and provide the background level of immunity in the general population aged 19-49 years. CD4 counts offer a measure of a person's immune function and can also be used to monitor trends in infection in the young population over time. The smoking habits of healthy control groups, however need to be taken into account especially when comparing the numbers of $\mathrm{T}$ cells and CD4 lymphocyte subpopulations from patients with different diseases to normal controls. Moreover, the value added of the present study resides in its finding vis-à-vis the age group of people most affected with HIV.

Through this study, we concluded that the international standards of classification of the HIVinfected subjects according to their rates of CD4 are applicable to the young Moroccans population.

\section{Acknowledgements}

The authors would like to acknowledge the Professor Abdesslam Badr from the American language center for his proof reading of the manuscript.

\section{References}

1. Lee BW, Yap HK, Chew FT, Quah TC, Prabhakaran K, Chan GS, Wong SC, Seah CC. Age- and sex-related changes in lymphocyte subpopulations of healthy Asian subjects: from birth to adulthood. Cytometry. 1996, 15;26(1):815

2. Mills PJ, Ziegler MG, Dimsdale JE, Parry BL.Enumerative immune changes following acute stress: effect of the menstrual cycle. Brain Behav Immun. 1995;9(3):190-5.
3. Choong ML, Ton SH, Cheong SK.Influence of race, age and sex on the lymphocyte subsets in peripheral blood of healthy Malaysian adults. Ann Clin Biochem. 1995 ;32 ( Pt 6):532-9

4. Uppal SS, Verma S, Dhot PS.Normal values of CD4 and CD8 lymphocyte subsets in healthy indian adults and the effects of sex, age, ethnicity, and smoking. Cytometry B Clin Cytom. 2003; 52(1):32-6.

5. Sellar CM, Syrotuik DG, Field CJ, Bell GJ. The effect of dietary control and carbohydrate supplementation on the immune and hormonal responses to rowing exercise. Appl Physiol Nutr Metab. 2006;31(5):588-96.

6. Jeong IG, Han KS, Joung JY, Choi WS, Hwang SS, Yang SO, Seo HK, ChungJ, Lee KH. Analysis of changes in the total lymphocyte and eosinophil count during immunotherapy for metastatic renal cell carcinoma: correlation with response and survival. J Korean Med Sci. 2007;22 Suppl:S122-8

7. Centers for Disease Control. Guidelines for the performance of CD4+/ T-cell determinations in persons with human immunodeficiency virus infection. MMWR Recomm. Rep 1992; 41 (RR-8) $1-17$.

8. Centers for Disease Control. Revised Guidelines for Performing CD4+ T-Cell Determinations in Persons Infected with Human Immunodeficiency Virus (HIV). MMWR 1997; 46 (no. RR-2):1-29.

9. Freedman DS, Flanders WD, Barboriak JJ, Malarcher AM, Gates L. Cigarette smoking and leukocyte subpopulations in men. Ann Epidemiol. 1996; 6(4):299-306

10. Sunyer J, Muñoz A, Peng Y, Margolick J, Chmiel JS, Oishi J, Kingsley L, Samet JM. Longitudinal relation between smoking and white blood cells. Am J Epidemiol. 1996;144(8):734-41.

11. Schaberg T, Theilacker C, Nitschke OT, Lode H. Lymphocyte subsets in peripheral blood and smoking habits. Lung. 1997;175(6):387-94.

12. Shahabuddin S, al Ayed IH, el-Rad MO, Qureshi MI. Lymphocyte subset reference ranges in healthy Saudi Arabian children. Pediatr Allergy Immunol. 1998;9(1):44-8)

13. Santagostino A, Garbaccio G, Pistorio A, Bolis V, Camisasca G, Pagliaro P, Girotto M.An Italian national multicenter study for the definition of reference ranges for normal values of peripheral blood lymphocyte subsets in healthy adults. Haematologica. 1999;84(6):499-504. 
14. Ampofo W, Torpey K, Mukadi YD, Koram K, Nolan K, Amenyah R, Kaitoo E, Antwi P, OforiAdjei D, Lamptey P. Normal CD4+ T lymphocyte levels in HIV seronegative individuals in the Manya/Yilo Krobo communities in the Eastern region of Ghana. Viral Immunol. 2006; 19(2):260-6.

15. Kaaba SA, Al Fadhli S, Khamis A.Reference values of lymphocyte subsets in the normal healthy adult Kuwaiti Arab population. Immunol Lett. 2002; 81(3):199-203

16. Pacifici R, Zuccaro P, Cozzi-Lepre A, di Carlo S, Bacosi A, Fattorossi A.Quantification of the variation due to lysing technique in immunophenotyping of healthy and HIVinfected individuals. Clin Biochem. 1998; 31(3):16572
17. Ruiz AR, Fernández IP, Perea Baena JM, de La Torre FJ, Ramírez GR.Influence of sample storage time and temperature on lymphocyte subset counts using a FACScount system. Haematologica. 2000; 85(5):550-1

18. Barnett D, Granger V, Whitby L, Storie I, Reilly JT. Absolute CD4+ T-lymphocyte and CD34+ stem cell counts by single-platform flow cytometry: the way forward. BrJ Haematol. 1999; 106(4):1059-62.

19. Schnizlein-Bick CT, Spritzler J, Wilkening CL, Nicholson JK, O'Gorman MR. Evaluation of TruCount absolute-count tubes for determining CD 4 and CD 8 cell numbers in human immunodeficiency virus-positive adults. Site Investigators and The NIAID DAIDS New Technologies Evaluation Group. Clin Diagn Lab Immunol. 2000; 7(3):336-43. 